\title{
Model of Segmentation of Rocket Fairings Due to the Action of a Cumulative Charge
}

\author{
Marina Chernobryvko ${ }^{1}$, Konstantin Avramov ${ }^{1}$, Boris Uspensky ${ }^{1}$, Anatoly Tonkonogenko ${ }^{2}$, and Leopold Kruszka ${ }^{3, *}$ \\ ${ }^{1}$ A.N. Podgorny Institute for Mechanical Engineering Problems, National Academy of Sciences of Ukraine, 61046, Kharkiv, Ukraine \\ ${ }^{2}$ Yangel Yuzhnoye State Design Office, 49008, Dnipro, Ukraine \\ ${ }^{3}$ Military University of Technology, Civil Engineering and Geodesy Faculty, 00-908, Warsaw, Poland
}

\begin{abstract}
Safe separation of the rocket payload fairing is one of the most important factors that affect the success of a flight mission. In recent years, composite materials instead of aluminum alloys are widely used in rocketry. Such materials must satisfy a number of requirements that include the certainty of a local failure due to the action of a cumulative charge of the given power. To analyze this process numerical research is an advisable approach. The model of a composite rocket fairing separating due to the action of a cumulative charge has been developed. The properties of the composite material have been modeled based on the averaged characteristics obtained experimentally. The cumulative charge has been modeled by impulse loading having parameters adequate to the charge type. The time of action of the impulse, maximum pressure and width of the loading area are determined from the charge properties and geometry. The rocket fairing is considered as a composite shell composed of conical and cylindrical parts. A technique for 3D numerical analysis of the dynamic strength and structural failure has been developed. The mathematical model of the structure deformation and failure takes into account the dynamical properties of the material. The maximum plastic deformation is used as a failure criterion. The results of numerical simulation for the typical rocket payload fairing are presented.
\end{abstract}

\section{Introduction}

Composite materials have been widely used in modern rocket engineering. The casings of rockets are produced from composite materials. The parameters of thin-walled composites casings are chosen from different criterions. For example, the stresses of the thin-walled casings satisfy the strength criterion. The filament- wound cylinder made for the booster motors of the Space Shuttle is analyzed experimentally under the action of impacts by Poe [1]. It is stressed [2], that the vibrations of the motor casing play a significant role in altering the combustion behavior of the propellant grain. Finite element model was established by $\mathrm{Qu}$ and Zhan [3] to simulate amplitudes of Mises stresses. The dependence of the mechanical properties of composite modified double base propellant on the strain rate is investigated in [4]. The method for measuring the pressure coupled response of composite propellant is suggested in [5]. A numerical approach for simulating the fluid-solid interaction problems in the ignition transient is suggested by $\mathrm{Li}$, Liu, He [6]. It is stressed [7], the dynamic behavior analysis of this thin-walled structure under the action of impact loads is performed. The tasks of the dynamic behavior of the elements of constructions under the impulsive loadings modeling are examined in [8]. Numerical calculations of the dynamic stress-strain state for steel constructions are conducted for a local impulsive loading. In [9] alternative technical solutions for solving the allocation of the impact area for the leaf of the payload fairing of launch vehicles are considered, including technology-based aerodynamic maneuvers and the burning of the segment of the payload fairing with the use of pyrotechnic composition.

The dynamic behavior and segmentation of the composite rocket fairings conical part under the action of internal impact pressure is treated in this paper.

\section{Problem formulation and modeling}

The dynamic strength and failure of the rocket fairing under the cumulative charge is investigated. The fragment of rocket fairing is shown in Fig. 1. The destruction of a truncated conical shell is modeled.

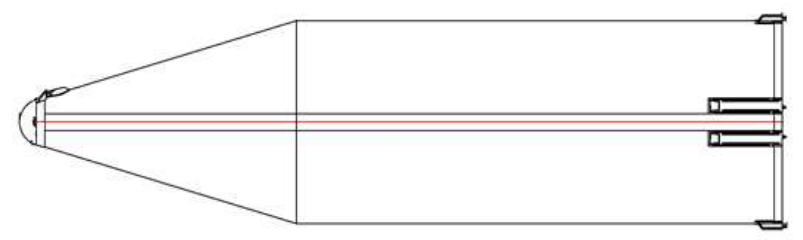

Fig. 1. The sketch of rocket fairing.

The action of the cumulative charge is modeled by a local impulse pressure. This pressure varies with time according to a given law. The time of impulse action,

*Corresponding author: leopold.kruszka@wat.edu.pl 
maximum pressure and the width of the loading area are determined from the properties of cumulative charge. The following model of impulse pressure was used:

$$
\begin{gathered}
P_{\text {ext }}\left(x_{i}, t\right) \leq P_{\text {cr }}\left(x_{i}, t\right) \\
P_{\text {ext }}=P_{\mathrm{x}} \exp \left(-a\left(\delta / r_{\mathrm{ch}}\right)^{b}\right)
\end{gathered}
$$

where $P_{\text {ext }}-$ shock pressure on the external; $P_{\text {cr }}-$ critical pressure of segmentation; $P_{\mathrm{x}}-$ internal pressure; $a, \delta, r_{\mathrm{ch}}$, $b$ - empirical coefficients of cumulative charge.

The model of truncated conical shell with loads and fastenings are presented in Fig. 2. The critical pressure is $P_{\mathrm{cr}}=1770 \mathrm{MPa}$. The shock pressure has magnitude of $1770 \mathrm{MPa}$ that is maintained for $14 \mu \mathrm{s}$ between time points of 2 and $16 \mu \mathrm{s}$.

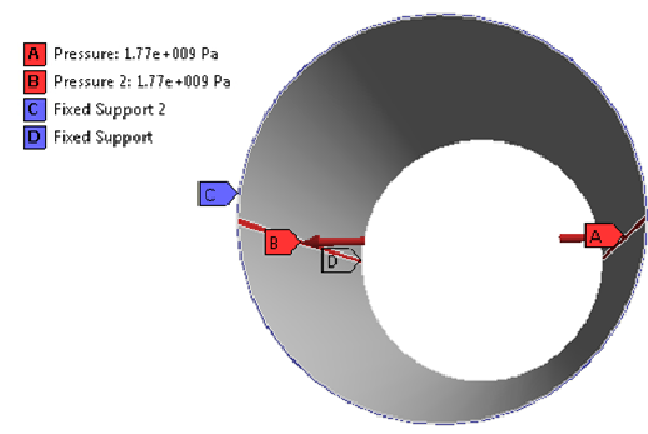

Fig. 2. The calculation model of truncated conical shell with loads (pressure) and fastenings (fixed supports).

The material of the truncated conical shell is aluminum composite. The computations were performed in the assumption that the parts were made of AlSi10Mg powder material. Based on analyzing data $[10 \div 13]$ for AlSil0Mg, the following values were used: density $\rho=$ $2.670 \mathrm{~kg} / \mathrm{m}^{3}$, elasticity modulus $E_{\mathrm{x}}=E_{\mathrm{y}}=70 \mathrm{GPa}$, $E_{\mathrm{z}}=60 \mathrm{GPa}$, Poisson coefficient $v=0.33$, proportional elastic limit $\sigma_{\mathrm{y}}=240 \mathrm{MPa}$, yield value $\sigma_{\mathrm{U}}=345 \mathrm{MPa}$. Plastic flow is considered for the Cowper-Symonds Strength model.

\section{Numerical simulation}

The problem is solved by the 3D finite element method (Fig. 3). The shell is the truncated cone: length $L=1.6$ $\mathrm{m}$ with radiuses $R_{1}=0.34 \mathrm{~m}$ and $R_{2}=0.2 \mathrm{~m}$, its thickness $h=4 \mathrm{~mm}$. The cumulative charges are modeled by two bands of local pressure along a formative shell with width of $s=3 \mathrm{~mm}$.

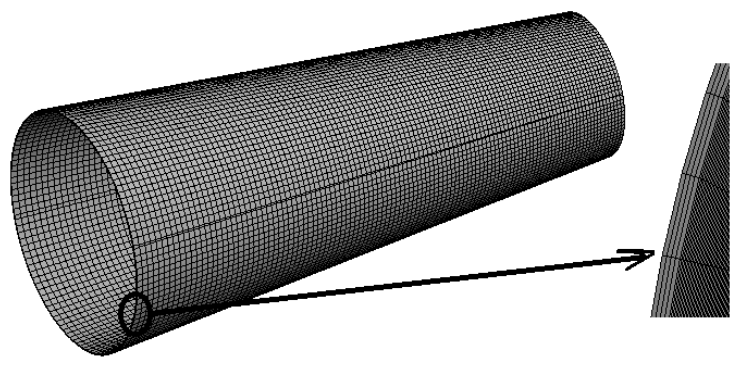

Fig. 3. The finite element model (about 52 thousands elements).
The time of the dynamic rocket fairing failure is analyzed. The calculation time is synchronized with the loading time. Equivalent plastic strain at calculation time point of $14 \mu \mathrm{s}$ is shown in Fig. 4. The plastic deformations are localized in the loading zone, the destruction has not occurred. At calculation time point of $21 \mu \mathrm{s}$ the upper part of the truncated cone begins to separate (Fig. 5). The disengagement process ends in $27 \mu$ s, which is shown in Fig. 6.

The numerical simulation analysis shows the following: a limit state in the truncated conical shell is obtained at $21 \mu \mathrm{s}$; a plastic deformation is localized at the thickness of the shell near loading zones. The construction fails along loaded zones from $21 \mu$ s to $27 \mu \mathrm{s}$.

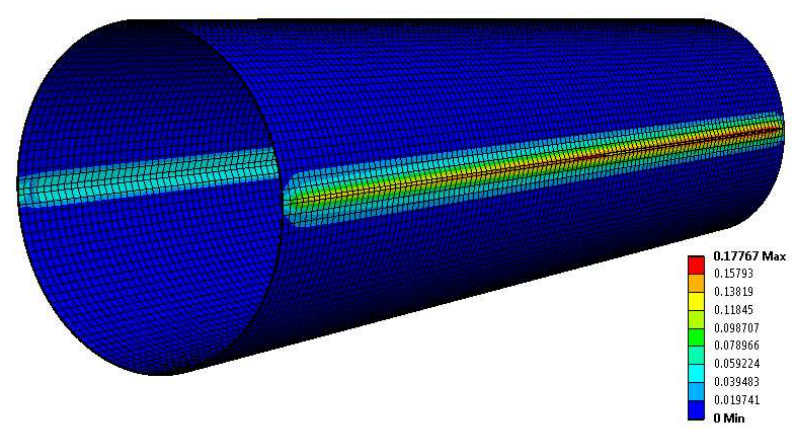

Fig. 4. Distribution of equivalent plastic strain at the calculation time point of $14 \mu \mathrm{s}$.

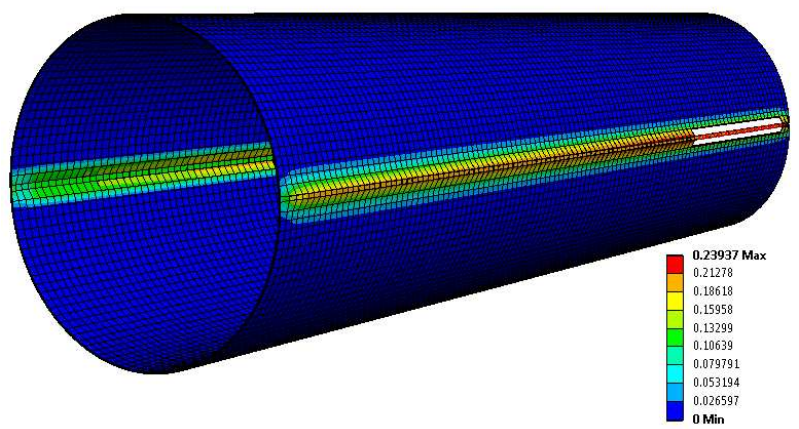

Fig. 5. Distribution of equivalent plastic strain at the calculation time point of $21 \mu \mathrm{s}$.

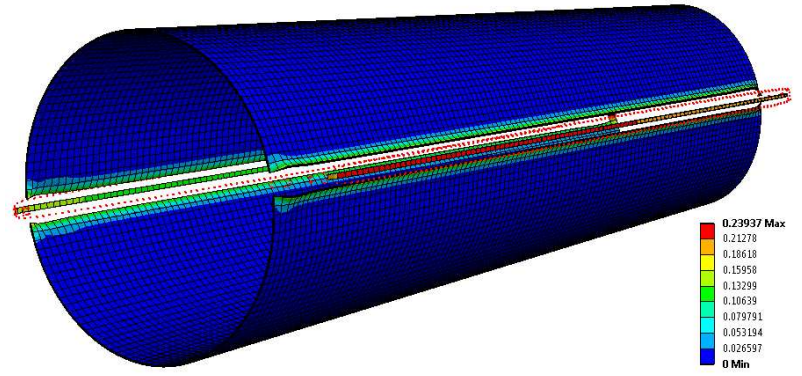

Fig. 6. Distribution of equivalent plastic strain at the calculation time point of $27 \mu$ s.

Fig. 7 and Fig. 8 show the equivalent stress and deformations at the time $27 \mu$ s respectively. The equivalent stress and deformations are localized in the loading zone likewise. 


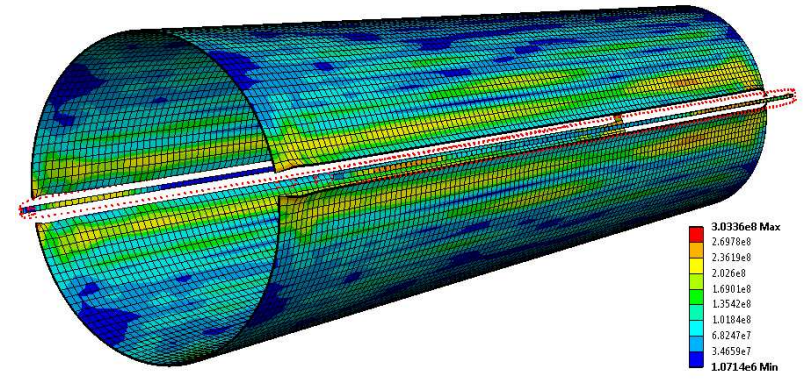

Fig. 7. Distribution of equivalent stress (unit: $\mathrm{Pa}$ ) at the calculation time point of $27 \mu$ s.

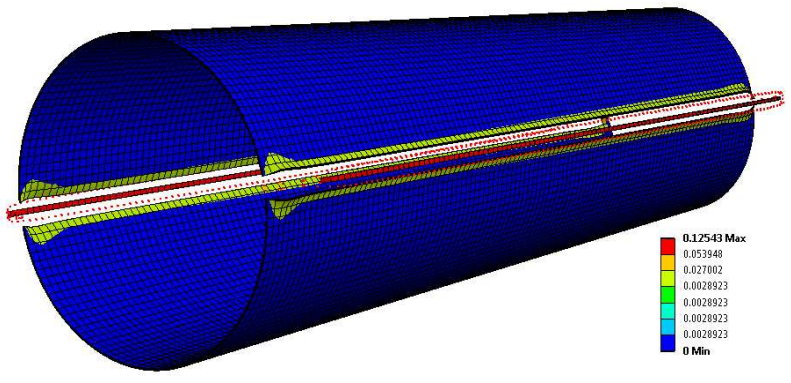

Fig. 8. Distribution of total deformations at the calculation time point of $27 \mu$ s.

In Fig. 9 the dynamics of the fairing parts after the destruction is shown as a sequence of states at time frames of 27 and $100 \mu \mathrm{s}$. The red lines represent the degraded finite elements destroyed during simulation.

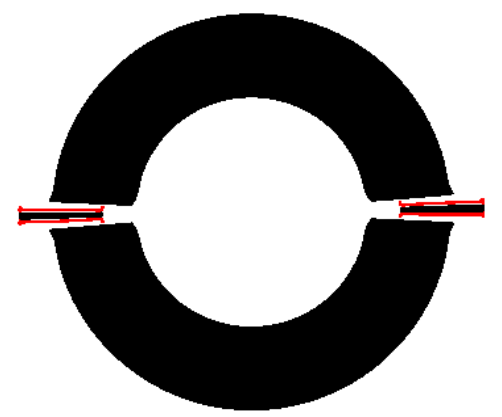

a)
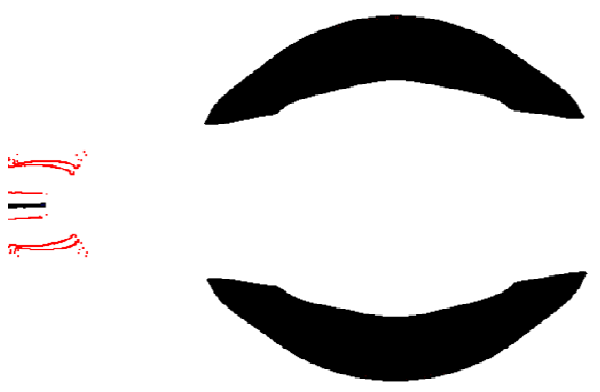

b)

Fig. 9. The dynamics of the fairing parts after the destruction: at the calculation time point $\mathrm{t}=27 \mu \mathrm{s}$; b) at the calculation time point $\mathrm{t}=100 \mu \mathrm{s}$.

\section{Summary}

This work presents the model of the safe separation of the rocket payload fairing. To analyze this process numerical research is an advisable approach. The model of a composite rocket fairing separating due to the action of a cumulative charge has been developed. The properties of the composite material have been modeled based on the averaged characteristics obtained experimentally. The cumulative charge has been modeled by impulse loading having parameters adequate to the charge type. The time of action of the impulse, maximum pressure and the width of the loading area are determined from the charge properties and geometry. The technique for 3D numerical analysis of the dynamic strength and structural failure has been developed. The mathematical model of the structure deformation and failure takes into account the dynamical properties of the material. The maximum plastic deformation is used as a failure criterion. The results of numerical simulation for the typical rocket payload fairing are presented.

This research is partially supported by the grant of the National Academy of Sciences of Ukraine on space research for 20182022.

\section{References}

1. C. C. Poe, J. Spacecraft and Rockets, 29, 394 (1992)

2. J. Montesano, K. Behdinan, D. R. Greatrix, Z. Fawaz, J. Sound Vibr., 311, 20 (2008)

3. K. Qu, X. Zhan, Propulsion and Power Research, 2, 50 (2013)

4. L. Yang, N. Wang, K. Xie, X. Su, S. Li, Polym. Test., 51, 49 (2016)

5. W. Su, N. Wang, J. Li, Y. Zhao, M. Yan, J Sound Vibr., 333(8), 2226 (2014)

6. Q. Li, G. He, P. Liu, J. Li, Computers and Fluids, 93, 146 (2014)

7. M.V. Chernobryvko, K.V. Avramov, L. Kruszka, A.M. Tonkonogenko, Key Eng. Mater, 715, 237 (2016)

8. M.V. Chernobryvko, L. Kruszka, Yu.S. Vorobiev Appl. Mech. Mater, 566, 493 (2014)

9. V. Trushlyakov, D. Davydovich, Procedia Engineering, 174, 4 (2017)

10. E. Brandl, U. Heckenberger, V. Holzinger, D. Buchbinder, Materials and Design, 34, 159 (2012)

11. K. Kempen, L. Thijs, J. Humbeeck, J.-P. Kruth, Physics Procedia, 39, 439 (2012).

12. M. Leary, M. Mazur, J. Elambasseril, M. McMillan, Th. Chirent, Y. Sun, M. Qian, M. Easton, M. Brandt, Materials and Design, 98, 344 (2016)

13. M. Tang, P.C. Pistorius, Int. J. Fatigue, 94, 192 (2017) 
